\title{
A RELAÇÃO ENTRE LITERATURA DE CORDEL E MÍDIA: UMA REFLEXÃO ACERCA DAS IMPLICAÇÕES PARA O GÊNERO
}

\section{Viviane de Melo Resende}

\section{ABSTRACT:}

In this paper, I focus the Brazilian literatura de cordel, popular literature in verse, typical of Brazilian Northeast. The paper is based on interviews, carried through between 2002 and 2004, with diverse social actors involved in the production of the cordel. The interviews were carried through in Campina Grande (PB), Caruaru, Bezerros and Recife (PE), Juazeiro do Norte and Fortaleza (CE) and in Rio de Janeiro, where there is the Brazilian Academy of Literatura de Cordel $(A B L C)$. The objective of the paper is thinking the relations of the cordel with the media and the implications of these relations for the cordel as social and discursive practice.

KEY WORDS: popular literature; ethnographic interviews; media.

INTRODUÇÃO ${ }^{1}$

Neste trabalho, dedico-me a uma reflexão acerca da literatura de cordel brasileira, literatura popular em verso, típica do Nordeste do País. Para essa discussão, baseio-me sobretudo em 12 entrevistas realizadas entre 2002 e 2004 com diversos atores sociais implicados na produção do cordel, em Campina Grande (PB), Caruaru, Condado, Bezerros e Recife (PE), Juazeiro do Norte e

\footnotetext{
${ }^{1}$ Este trabalho é um recorte da dissertação de Mestrado intitulada "Literatura de cordel no contexto do novo capitalismo: o discurso sobre a infância nas ruas", defendida em março de 2005 junto ao Programa de Pós-Graduação em Lingüística, da Universidade de Brasília. A dissertação foi publicada integralmente no TELA 3 - Textos em Lingüística Aplicada, organizado por Vilson J. Leffa. Este recorte foi apresentado no seminário Práticas socioculturais ediscurso: debatestransdisciplinares, organizadopeloNúcleodeEstudos de Linguagem e Sociedade (NELiS), do Centro de Estudos Avançados Multidisciplinares (CEAM), da Universidade de Brasília, em março de 2006.
} 
Fortaleza (CE), e a cidade do Rio de Janeiro, onde se localiza a Academia Brasileira de Literatura de Cordel. Foram entrevistados dez cordelistas, um editor e uma editora de cordel, que contribuiram gentilmente com minha pesquisa respondendo a questões acerca da produção, da distribuição e do consumo de cordel nos períodos de produção tradicional e contemporânea. ${ }^{2}$

O objetivo do ensaio é refletir acerca das relações do cordel com a mídia e das implicações dessa relação para o cordel como gênero e como prática social. Considerando que os gêneros do discurso são sensíveis a mudanças na prática social de que participam, e que a vida social é constituída de práticas e redes de práticas definidas por articulações relativamente estáveis entre os momentos dessas práticas, concluo que as transformações pelas quais passou o cordel são uma questão de como se articulam os momentos da prática e de que elementos da prática social são trazidos, articulados e internalizados.

\section{LITERATURA DE CORDEL: GÊNERO DISCURSIVO E PRÁTICA SOCIAL}

Os gêneros do discurso são sensíveis a mudanças na prática social de que participam. Segundo Bakhtin (2000 [1979]: 285), "de uma forma imediata e ágil, refletem a menor mudança na vida social”. A vida social é constituída de práticas e redes de práticas sociais, e as práticas sociais são definidas por articulações relativamente estáveis entre os momentos dessas práticas - tipos de atividade, ligados de maneiras particulares a condições materiais, temporais e espaciais específicas; pessoas particulares com suas experiências, disposições e conhecimentos; fontes semióticas particulares e maneiras de uso da linguagem específicas (Chouliaraki \& Fairclough, 1999, com base em Harvey, 1992).

Assim, transformações em gêneros discursivos refletem transformações nas articulações de momentos das práticas sociais a que se filiam. As transformações pelas quais passou o cordel são uma questão de como se articulam os momentos da prática e de que elementos da prática social são trazidos, articulados e internalizados. A articulação entre os momentos da prática do cordel

\footnotetext{
${ }^{2}$ Registro aqui meu agradecimento a Ana Ferraz, Gonçalo Ferreira da Silva, Vicente Pereira, José Lourenço, Rouxinol do Rinaré, Manoel Monteiro, Abraão Batista, J. Borges, J. Miguel, José Costa Leite, Mestre Azulão e Klévisson Viana.
} 
foi modificada, mas há uma grande resistência de teóricos/as em registrar a mudança. Um exemplo dessa resistência é a definição de literatura de cordel de Mark Curran (1998: 17). Vejamos:

A literatura de cordel é uma poesia folclórica e popular com raízes no Nordeste do Brasil. Consiste, basicamente, em longos poemas narrativos, chamados "romances" ou "histórias", impressos em folhetins ou panfletos de $32 \mathrm{ou}$, raramente, 64 páginas, que falam de amores, sofrimentos ou aventuras, num discurso heróico de ficção. Esta é uma parte significativa do cordel em termos de número de poemas publicados, mas nem de longe representa todo o gênero. Um segundo tipo de impresso, o folheto com oito páginas de poesia circunstancial ou de acontecido, também contribui para o corpus total. Completa o quadro o duelo poético, chamado "peleja", "desafio" ou termo equivalente. Assim, o cordel tem características tanto populares quanto folclóricas, ou seja, é um meio impresso, com autoria designada, consumido por um número expressivo de leitores numa área geográfica ampla, enquanto exibe métricas, temas e performance da tradição oral. Além disso, conta com a participação direta do público, como platéia.

Assim como a maior parte das definições de cordel encontradas na literatura especializada, essa de Curran bem caracteriza o cordel tradicional, mas não acrescenta as marcantes modificações que se pode observar no gênero na contemporaneidade.

Diegues Jr. (1977) registra que na década de 1970 a realização mais comum no cordel eram os chamados 'romances'. Se no período tradicional os romances eram mais numerosos que os folhetos circunstanciais, hoje se observa o contrário: a maior parte da publicação atual é de folhetos circunstanciais de oito páginas ou, no máximo, 16 - excluídas, é claro, as reedições de clássicos do período tradicional.

A "participação direta do público como platéia" já não se verifica: o cordel migrou das feiras e mercados nordestinos para lojas de artigos turísticos e aeroportos - donde se inferem mudanças com relação ao público consumidor 
- e é vendido por comerciantes, o que elimina o contato direto do/a cordelista com seu público. Nas entrevistas que realizei, foram freqüentes as referências aos contextos de venda dos períodos tradicional e contemporâneo. A seguir, nos excertos da ilustração (1), listo alguns depoimentos:

(1) (a) Hoje não tem mais essa questão da oralidade, do poeta recitar um pedacinho. Não tem mais isso. Não tem mais aquela coisa do cara vender... Porque o que eu achava bonito demais era que o cara mandava fazer o cordel, jogava na sua malotinha quadrada de couro. Jogava debaixo do braço e se danava para a feira vender o seu cordel. Aquilo que era bonito (José Lourenço).

(b) Porque hoje em dia não existe nem o poeta que lê em feiras livres, não tem. O contexto de venda do cordel, não é mais na mão do cordelista que se compra, não. Hoje as pessoas ligam pra editora ou ligam pro cordelista, que envia pelo correio. Ou nas livrarias. Mas esse tipo de trabalho dos poetas venderem diretamente em feiras realmente está se acabando, não tem mais... (Ana Ferraz).

(c) Antigamente eu vendia lendo na feira. Serviço de som, botava um microfone aqui e ficava com um cordel, explicando com a mão (José Costa Leite).

(d) Vendia o cordel nas praças, nas feiras, nas festas. Aonde tinha a regência de muita gente, a gente ia. Eram muitos cordelistas aqui no Nordeste. Toda feira, sempre tinha cinco, seis cantando, fazendo aquelas rodadas de gente. Cada um beco na rua, um fim de feira assim, um espaço, tinha um cordelista. Aquilo foi diminuindo, diminuindo, hoje você anda dez feiras, vinte feiras, cinqüenta feiras no Nordeste e não vê um. O cantador de cordel mesmo, ele não existe mais (J. Borges).

(e) E é lógico que a literatura de cordel abandonou aos poucos os pontos de resistência tradicionais: as feiras, as casinholas do 
subúrbio, as fazendas, os mercados e partiu para outra, para nova finalidade, a literatura de cordel (Gonçalo Ferreira da Silva).

Assim como o contexto de distribuição foi profundamente modificado, também se modificaram as práticas de produção e consumo. Uma definição cuidadosa do cordel deve, pois, atentar para os diferentes períodos de produção, e só pode ser feita a partir da observação das práticas discursiva e social em cada um dos períodos. Um breve histórico da literatura de cordel pode ser útil para a compreensão de suas transformações.

Galvão (2001) registra que o primeiro folheto impresso localizado é de Leandro Gomes de Barros - considerado o maior nome dessa literatura: nas palavras de Klévisson Viana, "o primeiro sem segundo" - e data de 1893. Contudo, o apogeu da literatura de cordel deu-se somente nas décadas de 1930 e 1940, em que "montaram-se redes de produção e distribuição dos folhetos, centenas de títulos foram publicados, um público foi constituído, consolidandose o formato em que é impresso" (Galvão, 2001: 33).

Nesse período tradicional, o cordel era consumido, principalmente, pela população do interior do Nordeste e cumpria papel de informação e lazer coletivo, de socialização. Os folhetos eram lidos e ouvidos em voz alta, em "reuniões que congregavam parentes e vizinhos" (Galvão, 2001: 181). Quanto a sua importância como divulgador de notícias, Diegues Jr. (1977: xvii) registra:

Instrumento de comunicação, alargou-se depois à divulgação dos fatos acontecidos, coisas de que a população não podia ter conhecimento senão por essa forma. Rádio não existia; jornal era raro. Quando este chegava, levado dos grandes centros - Recife ou Fortaleza, por exemplo - com o atraso normal dos meios de transporte de então, já o folheto se antecipava na divulgação do fato. Tornava-se o folheto o elemento mais expressivo para que os acontecimentos chegassem ao conhecimento de todos, lidos nos mercados, nas feiras, nos serões familiares.

O cordel era considerado o 'jornal do Sertão'. Era por meio dele que as notícias chegavam ao interior do Nordeste. Nesse sentido, pode-se dizer que o cordel 
foi uma mídia importante na região. O depoimento de Gonçalo a esse respeito pode esclarecer a importância que o cordel assumia na difusão de informação:

(2) Era muito comum chegando as velhas locomotivas, as marias-fumaças, madrugarem nas estações ferroviárias naquele tempo, trazendo jornais com as notícias de maior impacto social e os camponeses dizendo: 'Não, rapaz, isso é conversa de jornal, rapaz! Você não acredite! Você só acredite se sair no cordel, no folheto, no fim da semana'. E assim foi com a própria morte de Getúlio Vargas na década de 50, em 54, né? E mais anteriormente com a morte de Corisco em 1940, com a morte do Lampião em 1938. E o pessoal não deu crédito nenhum aos jornais. $\mathrm{O}$ pessoal só dava crédito se realmente aparecesse uma notícia na literatura de cordel. E nesse fato da morte de Corisco, quando ele faleceu no dia 27 de maio de 1940, o pessoal desacreditou na notícia que o jornal trouxe. E só veio realmente ratificar com segurança a morte de Corisco quando, no fim da semana, saiu o folheto do Moisés Matias de Moura anunciando em 'martelo agalopado' a morte de Corisco.

A partir dos anos de 1950, a migração de populações nordestinas ao CentroSul do país fez migrar também a literatura de cordel. Assis Ângelo (1996: 76) registra que os primeiros cordelistas ${ }^{3}$ desembarcam em São Paulo nesse período e que a migração continuou intensa também nas décadas seguintes: "dos anos sessenta até aqui, centenas de folhetos foram escritos e publicados por cordelistas radicados em São Paulo". Os cordelistas entrevistados por Assis Ângelo justificam a migração pelas condições de venda de folhetos: "tanto no Rio como em São Paulo é muito mais fácil ganhar dinheiro do que no Nordeste".

Na década de 1960 o cordel passou por uma grande crise, voltando a ser centro de interesses a partir dos anos de 1970, porém já com outra importante modificação em sua prática discursiva: o público consumidor. Galvão (2001: 34) registra esse fato:

\footnotetext{
${ }^{3}$ A referência a 'os cordelistas' aqui não é uma ocorrência do chamado 'masculino genérico': a inserção de mulheres entre cordelistas é posterior ao período mencionado, sendo característica do período contemporâneo de produção (Resende, 2005; 2007).
} 
Desta vez [tornou-se centro de interesse] principalmente por parte de turistas, universitários brasileiros e estrangeiros: o cordel tornou-se objeto de estudo e de curiosidade. Essa transformação do público leitor e, conseqüentemente, da produção também dos folhetos foi percebida pelos próprios poetas (...). A partir desse momento, os locais de venda começaram a mudar, o que também revela uma mudança de público: nas livrarias e lojas de artesanato (...). Atualmente, os folhetos são comprados, basicamente, por turistas e estudantes.

Essa modificação do público consumidor também foi registrada por cordelistas nas entrevistas. Vejamos, em (3), dois trechos em que essa mudança é percebida:

(3) (a) Está havendo uma procura muito grande, até costumo dizer que o cordel mudou de público. Porque, a partir do momento que a televisão penetrou no interior do estado, as pessoas mais velhas raramente lêem cordéis. Elas querem ver a novela, ver o filme. E hoje o público das escolas, que eu acho que é o novo público do cordel, e é um público que eu acho interessante, a gente aposta nesse público porque é uma nova geração. Quem sabe vai surgir atrás dessa nova geração novos poetas para dar continuidade à nossa cultura? Então eu acho que o cordel nunca morreu. Esteve num embate, aí houve uma renovação (Rouxinol do Rinaré).

(b) Eu acho que o que houve mesmo foi uma mudança grande. Porque você analisa o seguinte: antigamente o folheteiro pegava o seu poema, seus folhetos, ia para a feira livre. Chegava lá, ele tinha que cantar aquele folheto para o público. Porque o público era 80 a $90 \%$ analfabeto. Então, uma coisa é você lidar com um público dessa natureza. Hoje, por exemplo, é exatamente o oposto. Eu acho que houve realmente uma revolução porque o público mudou, né? (Klévisson Viana). 
Além dos/as consumidores/as, também os/as poetas cordelistas já não são os/as mesmos/as. Abreu (1999) registra que a maioria dos poetas das três primeiras décadas do século XX nasceu na zona rural e teve pouca ou nenhuma instrução formal. Os/as cordelistas contemporâneos/as, assim como os/as consumidores/as de cordel hoje, têm maior acesso à cultura letrada. Há também poetas ditos/as eruditos/as, que escrevem não por profissão, mas por lazer, e são vistos/as com desconfiança pelos/as mais conservadores/as. Vejamos a ilustração (4), a seguir:

(4) No tempo que o povo era analfabeto, mas conhecia o cordel e conhecia a rima, quando a pessoa lia um cordel que a rima quebrava, o cara analfabeto já dizia logo: 'Epa, aí tá errado'. Agora não, agora o povo todo sabe ler, mas não entende, passa por cima da rima errada. (...) Aí aquilo ofende muito o cordel. Eu gostaria que esse povo, esses professores, doutores, esse povo ficasse só lendo o cordel e não metesse a escrever porque está esculhambando o ambiente. E tem uns professores que inventam de escrever cordel, faz até graça. Porque aí eles se agarram com a gramática e se esquecem que cordel não existe gramática para um cordel. A gramática de cordel é a rima positiva e as sílabas medidas. Aí dá o tempero da poesia (J. Borges).

Sobre o início dessa mudança na produção, Souto Maior (1976: 14) discorre:

Os poetas populares estão enveredando por outros caminhos, uma vez que não são tão semi-analfabetos como eram há algumas décadas passadas e estão participando do desenvolvimento da região e, através de seus folhetos, eles enviam suas mensagens, instruindo o povo que assim toma conhecimento dos problemas nacionais (...) Este novo impulso que está tomando a literatura popular em verso constitui, evidentemente, uma prova de que o folheto não está morrendo mas sofrendo modificações em seu conteúdo e atualização em sua temática. 
A escassez de histórias românticas na produção contemporânea ilustra esse fato. $\mathrm{O}$ cordel tradicional cumpria, com os romances e histórias de princesas e países longínquos, papel semelhante ao que hoje se pode atribuir à novela televisiva; mas essa sua função já não é marcante, talvez justamente pela popularização da TV com seus romances em capítulos. Nas palavras de José Lourenço: "eu considero aqueles cordéis antigos como se fossem as novelas de hoje, os filmes".

Outra função social que era desempenhada pelo cordel tradicional e que não se observa hoje é a de alfabetização. Muitos estudos fazem referência ao papel dos folhetos na alfabetização de um número expressivo de pessoas, de modo autodidata, principalmente durante seu apogeu. Sobre essa função do cordel, Galvão (2001: 186) registra:

Os depoimentos parecem indicar que a alfabetização por meio do cordel dava-se de maneira autodidata: através da memorização dos poemas, lidos ou recitados por outras pessoas, o "alfabetizando", em um processo solitário de reconhecimento das palavras e versos, procedia, ele mesmo, à aprendizagem inicial da escrita. Em outros casos, o folheto aparece como o principal motivador para que os meios formais de aprendizado da leitura e da escrita fossem procurados.

Com a expansão do sistema formal de ensino e com a 'despopularização' do cordel, essa função social relacionada à alfabetização e ao primeiro contato com a cultura letrada desaparece. Hoje se procura resgatar a utilização da literatura popular em sala de aula, não como auxiliar nas primeiras letras, mas como atividade de leitura e valorização da cultura nacional. Exemplo disso é o livro Cordel na sala de aula, que tem "o propósito de contribuir para divulgação e apreciação da literatura de cordel no espaço escolar" (Pinheiro \& Lúcio, 2001: 8). Essa preocupação com o fortalecimento do vínculo entre o cordel e a educação também é registrada na coleção Heróis e Mitos, lançada pela Editora Tupynanquim, de Fortaleza.

O cordel contemporâneo cumpre um papel social engajado com questões sócio-políticas atuais, o que se dá de duas maneiras principais: o comentário 
de fatos reais ocorridos no Brasil e no mundo ou, mais raramente, a narrativa sobre problemas contemporâneos, acrescentando-se sempre juízos de valor (Resende, 2005, 2007). Ambos os casos constroem-se em folhetos circunstanciais, que raramente ultrapassam as oito páginas. Nesses casos, é marcante a recontextualização de materiais simbólicos oriundos da mídia na literatura de cordel, fato registrado nas entrevistas de Klévisson Viana, Abraão Batista e Gonçalo Ferreira da Silva. Este último afirmou que "o cordelista extrai da mídia o conteúdo do folheto. (...) Eu mesmo, se eu fizer um folheto sobre, digamos assim, sobre o presidente, eu colho informação no jornal, na televisão".

\section{CoRdel E MídiA}

A recontextualização de notícias no cordel é, geralmente, crítica. Tome-se como exemplo alguns folhetos publicados a respeito da invasão liderada pelos Estados Unidos ao Iraque: Sem essa de guerra, de Luis Pimentel; George Bush quer guerra, é inimigo da paz, de Allan Salles; Carta de Satanás ao amigo George Bush, de Zé da Madalena. A recontextualização crítica de materiais simbólicos veiculados na grande mídia está de acordo com a observação de Thompson (1998) acerca da recepção de produtos da mídia como uma atividade situada e criativa. Situada porque a recepção dos produtos, cada vez mais globalizados, é localizada, sempre está inserida em contextos específicos. Criativa porque os indivíduos trabalham o material simbólico que recebem, usam-no de acordo com seus propósitos, não são espectadores passivos. Thompson (1998: 45) observa que "as mensagens podem ser retransmitidas para outros contextos de recepção e transformadas através de um processo continuo de repetição, reinterpretação, comentário, riso e crítica".

A relação do cordel com a mídia não se limita à recontextualização de notícias. Na verdade, a história do cordel está atrelada à mídia de outras maneiras. Em primeiro lugar, cabe lembrar a discussão a respeito do cordel como um importante meio de comunicação no tempo em que era considerado o ‘jornal do Sertão’. O depoimento de Gonçalo Ferreira da Silva, a seguir, é uma boa ilustração disso.

(5) A partir de 1920, até chegar o momento culminante da literatura de cordel do Nordeste como veículo de comunicação, o folheto 
de cordel superou todos os veículos existentes no momento, até mesmo o jornal.

Em segundo lugar, uma relação entre o declínio da produção de cordel e a ascensão do rádio e da televisão no Nordeste costuma ser estabelecida por atores sociais envolvidos na produção de cordel. Na ilustração (6), listo alguns depoimentos sobre isso:

(6) (a) A literatura de cordel foi afogada por um período, por um determinado período com a evolução da informação. Afogada pela invasão da informação, o imediatismo da informação. E, veja bem, como entretenimento muito mais ainda (Manoel Monteiro).

(b) Antigamente eu vendia muito mais, é. O povo do campo não tinha uma TV. Hoje todo mundo tem. A TV Globo, eu penso que é a maior inimiga do poeta popular (José Costa Leite).

(c) Porque, antigamente, o cordel narrava primeiro, mas aí não tem como porque a imprensa está muito evoluída (Rouxinol do Rinaré).

É verdade que com a popularização do rádio e da televisão o cordel perdeu sua importância como difusor de notícias, como observa Rouxinol do Rinaré em (c). É verdade também que perdeu espaço como meio de entretenimento, conforme Manoel Monteiro ressalta em (a). Essa foi uma mudança importante da prática social que teve implicações também importantes para o gênero. De acordo com Gonçalo, a literatura de cordel teve de "se adequar ao meio".

Em sua discussão a respeito da interface entre a tradição e a mídia, Thompson (1998: 160) explica que "a tradição não foi destruída pela mídia, mas antes transformada ou 'desalojada' por ela”. Essa observação é útil para se pensar a relação entre cordel e mídia. Se por um lado o desenvolvimento dos meios de comunicação no Nordeste foi um "obstáculo" para a continuidade do gênero, por outro lado proporcionou os meios para a separação dessa prática 
tradicional de seu contexto inicial de produção, para seu desenraizamento. $\mathrm{O}$ desenraizamento, ainda segundo Thompson, é a condição para a reimplantação de práticas tradicionais em contextos diversos. Exemplos disso são as diversas referências ao cordel que podem ser encontradas na mídia. A revista Caros Amigos, por exemplo, publicou durante meses em 2003 pequenas matérias sobre cordel e outras manifestações populares, e a revista Cult publicou, em sua edição número 54, um dossiê de 21 páginas sobre a literatura de cordel. Os jornais impressos não ficam atrás: a Folha de S. Paulo publicou matérias sobre o tema em suas edições de 06 de outubro de 2001 e 06 de julho de 2002; O Estado de S. Paulo, em 3 de junho de 2002; o Correio Braziliense, em 07 de outubro de 2001 e 20 de dezembro de 2001. J. Borges foi tema de matérias no Correio Braziliense de 16 de abril de 2002 e no O Estado de S. Paulo de 15 de abril de 2002. Evidentemente, essas são apenas as publicações que pude acompanhar. É de se imaginar que haja outras.

Mas a relação entre o cordel e a mídia ainda não pára aí. Hoje há sítios na Internet ${ }^{4}$ que publicam literatura de cordel, como explica a reportagem do Correio Braziliense: "é na Internet que cordelistas da nova geração encontram espaço para divulgar e manter a tradição de um dos gêneros mais antigos da literatura popular". ${ }^{5}$ A observação do jornal está de acordo com a perspectiva de Thompson (1998: 178), que explica: "num mundo permeado pelos meios de comunicação, tradições se tornaram mais e mais dependentes de formas simbólicas mediadas, elas foram desalojadas de lugares particulares e reimplantadas na vida social de novas maneiras". E ele acrescenta que "o desenraizamento e a nova ancoragem das tradições não as tornam necessariamente inautênticas, nem as condenam à extinção".

Um outro ponto de tangência entre cordel e mídia diz respeito à recontextualização de outros elementos da mídia no cordel, além de notícias. Por exemplo, Abraão Batista publicou um folheto circunstancial de crítica política cujo título remete à Internet: www.juizlalau.fhc.acm.corrupção.ladrão.justiça. Rouxinol do Rinaré e Klévisson Viana estabeleceram uma outra recontextualização quando escreveram juntos um folheto de desafio, A grande peleja virtual

\footnotetext{
${ }^{4}$ Alguns exemplos são os sítios www.literaturadecordel.hpg.ig.com.br, www.ablc.hpg.com.br, www.cordelon.hpg.ig.br, www.mocoto.com.br, www.jangadabrasil.com.br.

${ }^{5} \mathrm{Na}$ edição de 20 de dezembro de 2001, na editoria Coisas da vida, página 08.
} 
de Klévisson Viana e Rouxinol do Rinaré, construído pela Internet, via correio eletrônico. Rinaré explica, no excerto de seu depoimento:

(7) É um cordel de peleja, uma peleja recriada. (...) eu fiz como Klévisson mesmo pela Internet. (...) Aí, o Klévisson estando lá na editora [Tupynanquim], a gente começou a mandar o e-mail de um para o outro, uma estrofezinha. E isso virou um desafio, não é? Depois juntamos tudo e fizemos a peleja, imprimimos a peleja. Foi feita totalmente virtual, mas depois impressa no folheto. E a gente diz aqui no final de uma nota que a gente casou a modernidade com a tradição, mantemos a tradição da poesia do cantador. Usamos os seus estilos como os cantadores usam na realidade, no repente mesmo, mas usamos de forma virtual. Mas a estrutura é a da poesia de cordel, não tem jeito. Então é isso. Eu acho assim é uma forma, se nós quisermos que a nossa cultura seja perpetuada, que outras gerações possam conhecê-la, nós temos que viver o nosso momento, mantendo a tradição do formato da poesia e da estrutura da poesia.

A relação entre o cordel e os meios de comunicação concerne também ao movimento entre a interação face a face e a quase-interação mediada. Assumindose como verdadeira a tese de Abreu (1999) quanto à filiação do cordel à cantoria, pode-se afirmar que essa literatura, oral na sua origem, evoluiu para a quaseinteração mediada, nos termos de Thompson (1998). Originalmente caracterizado pela interação face a face, que "acontece num contexto de co-presença", em que os participantes "partilham um sistema referencial de espaço-tempo", o cordel é hoje caracterizado pela quase-interação mediada, que "implica uma extensa disponibilidade de informação e conteúdo simbólico no espaço e no tempo - se dissemina no espaço-tempo" (Thompson, 1998: 78-9).

Isso me leva a retomar a discussão de Giddens $(1991$; 2002) a respeito da separação tempo-espaço e dos mecanismos de desencaixe. A separação de tempo e espaço permite a articulação de relações sociais ao longo de intervalos de espaçotempo, pois as sociedades modernas dependem de modos de interação em que as pessoas estão separadas temporal e espacialmente. Os mecanismos de desencaixe, por sua vez, referem-se à possibilidade de deslocamento de relações sociais de seus contextos e sua reestruturação através de extensões indefinidas de tempo-espaço. 
Nesse sentido, pode-se afirmar que o cordel, seguindo a tendência da comunicação moderna, adaptou-se à separação entre os contextos de produção e aqueles de consumo, alargando seu raio de alcance por meio de mecanismos de desencaixe. Se não fosse assim, como poderíamos, hoje, ter acesso a títulos de cordel publicados ao final do século XIX? Além dessa abordagem temporal do desencaixe, também importa salientar que desde o período de produção tradicional o cordel esmera-se em ultrapassar fronteiras geográficas. ${ }^{6}$ Assim é que, já na década de 1930, a figura do agente distribuidor de folhetos possibilitava a difusão do cordel em todo o Nordeste, como registra Gonçalo Ferreira da Silva:

(8) A compra por João Martins de Athayde do projeto editorial de Leandro Gomes de Barros em 1921 começou outra história pra literatura de cordel. João Martins de Athayde, um livro de época como a morte de Getúlio [Vargas], ele lançava 50.000. Por que 50.000 folhetos? Imagine só, em 1930 ele já tinha mais de 100 representantes, que ele chamava naquele tempo de agentes, cobrindo as principais cidades dos 9 estados do Nordeste.

A constituição dessa rede de distribuição denota a visão empresarial que esteve e está por trás da produção de cordel. Longe de ser uma prática destituída de organização e de visão comercial, a produção de cordel constitui-se como uma prática institucionalizada. Os núcleos de produção mantêm um vínculo comercial permanente por meio do intercâmbio de materiais, conforme me informaram Manoel Monteiro, Gonçalo Ferreira da Silva, Ana Ferraz e Klévisson Viana. Essa prática aumenta o raio de alcance dos produtos de todos os centros produtores interligados em uma rede. A tiragem inicial de um folheto depende de seu apelo comercial, como explica Klévisson Viana:

\footnotetext{
${ }^{6} \mathrm{O}$ deslocamento espacial do cordel ampliou-se ainda mais. Recentemente há edições de folhetos emlínguas estrangeiras, comoéocasode Enfants des rues et lemassacre de la Candelária e Un ethnologue suisse agressé au Brésil, traduzidos para o francês por Jean Louis Christianat em 2003e 2000 respectivamente; Tobias Barreto de Menezes von Sergipe in diewelte Mahatma Gandhi, versões em alemão e inglês, respectivamente, sem atribuição de tradução e data. Todos esses folhetos são traduções de originais de Gonçalo Ferreira da Silva editadas pela Academia Brasileira de Literatura de Cordel.
} 
(9) Quando o folheto não apresenta características que possa se autofinanciar, aí a gente procura fazer mil exemplares. Quando não, a gente faz dois mil, três mil. Até cinco mil exemplares de um título só a gente já tem feito de uma vez. (...) Tudo o que você faz de gracejo, de humor, é comercial. O que não é comercial, ao meu ver, geralmente as biografias de pessoas pouco conhecidas. Ou folheto de reportagem de matéria que não interessa mais para o público. Porque o folheto de reportagem tem uma vida útil.

A predominância de folhetos curtos, geralmente de oito páginas, também é uma questão comercial, atrelada ao aumento do preço do papel nos anos 1980, ainda segundo Klévisson Viana. A polêmica em torno da manutenção da tipografia como meio de produção do cordel ou sua substituição por métodos mais modernos de edição e impressão também tem fundo comercial. Sobre isso, Ana Ferraz explica: "o custo é muito alto e não existem mais peças para essas máquinas [antigas máquinas de tipografia usadas no período tradicional]". Malgrado o trabalho e o custo da manutenção do modo tradicional de produção, José Lourenço é um defensor da tipografia. Em suas palavras:

(10) A preferência é que a gente [da Lira Nordestina, em Juazeiro do Norte] continue com o tipo mesmo, não coloque off-set, nada disso. Porque perde a característica, é outra coisa, não fica mais tipografia. (...) e a gente vai insistir nessa coisa de segurar o cordel autêntico mesmo, como era feito antigamente e como hoje a gente ainda faz, com bastante dificuldade, mas a gente ainda consegue levar esse cordel. E é isso o que faz a diferença das editoras. É isso que a gente pretende segurar firme a tradição. E a gente vem lutando muito para preservar isso aqui, para ver se continua. É difícil.

Os demais cordelistas entrevistados não compartilham o ponto de vista de José Lourenço, pensam que a substituição da tipografia pelo offset é um benefício para a modernização do cordel. Listo a seguir alguns depoimentos. 
(11) (a) Agora tem uma minoria que é feita no manual ainda, tem uns cordéis aí que foi aqui feito no manual. Só que a maioria agora tá saindo mais off-set porque compensa mais por causa da impressão mais bem feita, a rapidez (J. Miguel).

(b) Eu acho que, dentro de muitos outros, eu respeito o ponto de vista [de José Lourenço]. Mas eu acho que se a gente for levar por esse extremo, aí vai chegar um período em que o cordel vai morrer mesmo porque vai faltar peças para as tipografias e a tipografia se acabando, acabaria o cordel porque querem que seja impresso em tipografia. (...) O poeta, ele tem que ser o poeta da sua época. $\mathrm{O}$ Leandro [Gomes de Barros] viveu a sua época, nós estamos vivendo outra época (Rouxinol do Rinaré).

(c) Aí você também não pode estar trabalhando hoje, com todos os recursos que dispomos, trabalhar como se estivesse na pré-história da imprensa. Não tem como. Eu não vou passar um mês trabalhando no cata-cata, juntando letrinha por letrinha para imprimir o folheto numa tipografia quando a gente dispõe de off-set (Klévisson Viana).

Essa controvérsia não é apenas uma questão de tradicionalismo; é, sobretudo, uma questão comercial. O mesmo é verdade para a transformação do contexto de distribuição, das feiras e mercados para os pontos turísticos, bancas de revista, livrarias, aeroportos. Klévisson Viana explica: “o sistema de vendas hoje é outro. Para mim é mais negócio. O poeta do passado não descobriu isso, mas para mim é mais negócio ter cem pontos de venda, do que eu ir para a feira. Eu vou estar em mais cantos ao mesmo tempo e trabalhando menos. É uma questão comercial".

Uma outra forma de distribuição do cordel que está se tornando uma prática convencional é a montagem de stands exclusivos para a venda desse produto em feiras de livro. Abraão Batista, que vem sempre à Feira do Livro de Brasília, afirma que esse é o caminho para "chegar à sociedade dominante". Ana Ferraz, da Editora Coqueiro, diz que "a feira é o grande furo" porque "é onde se vende mais, se divulga mais, se faz muito contato". Ela completa, 
lamentando não ter ido ainda às bienais do Rio de Janeiro e de São Paulo, "não creio que ninguém [do ramo do cordel] tenha grana para entrar". Ainda acerca da participação em feiras desse tipo, Ana Ferraz registrou um testemunho interessante, a respeito da desvalorização de produtos culturais tradicionais em face de produtos de grandes corporações globais:

(12) Aqui na Bienal [Bienal do Livro de Recife] mesmo eu senti um preconceito por parte dos próprios professores, eu não sei se era preconceito ou se era ignorância, porque não sabiam o que é literatura de cordel. Porque as crianças queriam encostar e eles puxavam pra ver aquelas coisinhas da Disney, onde tivesse uma editora que tivesse aqueles livrinhos de Branca de Neve, Cinderela, esses clássicos. E o cordel mesmo só quem procurava eram os pesquisadores, jornalistas, as pessoas com uma visão mais ampla, mas os próprios professores eu achei de uma ignorância que eu acredito que é porque não sabem explicar e falar sobre o cordel e a xilogravura, né? Eu fiquei com uma pena danada, logo aqui em Recife... Estar há 12 anos lutando com isso e ver os próprios professores com esse preconceito...

Esse depoimento da editora de cordel lembra a discussão de Jameson (2001) a respeito da faceta cultural da globalização. Para Jameson (2001: 54), o imperialismo cultural estadunidense pode estar na origem da destruição de tradições culturais que "representam acomodações recentes de velhas instituições à tecnologia moderna", como é o caso do cordel. Thompson (1998), por sua vez, vê com ressalva as teorias de imperialismo cultural, uma vez que seu foco recai sobre a recepção como uma atividade criativa e capaz de transformação. Já me estendi demasiado neste ensaio, e não pretendo aprofundar aqui essa discussão. Parece-me, entretanto, que embora a recepção dos produtos da mídia possa ser, evidentemente, uma atividade criativa - e os folhetos a respeito da chamada Guerra do Iraque mostram que de fato é assim -, a valorização de produtos de corporações internacionais pode acarretar uma desvalorização de produtos culturais tradicionais. José Costa Leite registrou essa desvalorização por parte dos mais jovens quando afirmou não serem raras as situações em que "rapaz de dez, doze anos sai mangando do cordel". 
Antes de fazer minhas considerações finais, quero ainda registrar um manifesto pelo apoio do poder público a manifestações da cultura popular. Para tanto, listo a seguir, em (13), uma série de protestos dos cordelistas entrevistados quanto à falta de políticas nesse sentido.

(13) (a) Eu me convenci que não tem jeito. É melhor não perder tempo. Cheguei à conclusão que o governo não atrapalhando já está ajudando muito. (...) Essas coisas de governo dá vontade até de desistir (Gonçalo Ferreira da Silva).

(b) Eu fiz aqui em Recife no ano retrasado [2002] um evento onde eu trouxe todos os cordelistas, assim, conhecidos, da Bahia, do Rio Grande do Norte, da Paraíba, do interior de Pernambuco, do Ceará; foi encontro de poetas e lançamento coletivo. Mas eu fiz tirando tudo do bolso porque governo nenhum entrou em parceria, né? (Ana Ferraz).

(c) Os poderes públicos não ajudam nada, os poderes públicos (...) prefeito, vereador, governador, ministro é tudo cego, não vê nada (José Costa Leite).

(d) O governo, os poderes públicos, não ligam importância. Isso aí, pode morrer a cultura, pode acabar que ninguém estava ligando nada, ninguém dá incentivo, ninguém dá ajuda, subsídio, nada disso aparece do lado público. (...) E aqui no Brasil, aqui eles protegem tudo na vida, mas quando fala em cordel, não tem proteção, não existe subsídio, não ajudam o poeta com nada, não querem nem saber. Não querem saber de nada disso (J. Borges).

\section{CONSIDERaÇões Finais}

Neste trabalho procurei contribuir para a reflexão acerca da literatura de cordel introduzindo algumas relações entre essa literatura popular e a mídia, de um lado, e o mercado editorial, de outro. Busquei enfatizar uma reflexão 
sobre o cordel que não 'pare no tempo', que não se limite a exaltar sua produção tradicional sem perceber os rumos que toma a produção contemporânea. Procurei também refletir acerca da produção de cordel na contemporaneidade, pensando sua relação inclusive com produtos culturais globalizados.

A discussão acerca das transformações operadas nas práticas discursiva e social do cordel, de seu período tradicional para seu período contemporâneo de produção, ilustra a dialética entre discurso e sociedade. Isso porque as transformações do gênero estão intimamente relacionadas a mudanças articulatórias nos momentos da prática do cordel e nas redes de prática das quais participa. Nesse sentido, procurei mostrar, com base nas entrevistas que realizei com diversos atores sociais envolvidos na prática do cordel, que as transformações na composição genérica e temática do cordel são uma adequação ao momento histórico em que se insere e à rede de práticas em que atua. A relação do cordel com os meios de comunicação de massa também foi alterada nesse processo, o que tem implicação na internalização e no questionamento de discursos hegemônicos em folhetos, como demonstrei na pesquisa de que esse ensaio é um recorte.

A reflexão acerca das transformações na literatura de cordel brasileira, de seu período tradicional para a produção contemporânea, nos termos aqui explorados, é também uma reflexão acerca de traços salientes de sociedades hodiernas, como a separação entre os contextos de produção e consumo, os mecanismos de desencaixe e a conseqüente externalização da reflexividade. Para que o estudo do cordel possa articular tais conceitos faz-se necessário, antes de tudo, o abandono à visão romântica ou folclórica acerca desse produto cultural, que passa a ser visto como prática social contextualizada no presente.

\section{REFERÊNCIAS BIBLIOGRÁFICAS}

ABREU, M. Histórias de cordéis e folhetos. Campinas: Mercado de Letras, 1999. ÂNGELO, A. A presença de cordelistas e cantadores repentistas em São Paulo. São Paulo: IBRASA, 1996.

BAKHTIN, M. Estética da criação verbal. São Paulo: Martins Fontes, 2000 [1979].

BATISTA,A. www.juizlalau.fhc.acm.corrupção.ladrão.justiça. SãoPaulo, s/ed., 2001. 
CHOULIARAKI,L.\&N.FAIRCLOUGH. Discourse in late modernity: rethinking critical discourse analysis. Edinburgh: Edinburgh University Press,1999. CURRAN, M. História do Brasil em cordel. São Paulo: Edusp, 1998.

DIEGUES JR., M. Literatura de cordel. Apresentação a Batista, S.N. Antologia da literatura de cordel. Natal: Gráfica Manimbu, 1977. pp. I-XXVI.

GALVÃO, A.M.O. Cordel: leitores e ouvintes. Belo Horizonte: Autêntica, 2001. GIDDENS, A. As conseqüências da modernidade. São Paulo: Editora Unesp, 1991. GIDDENS, A. Modernidade e identidade. Rio de Janeiro: Jorge Zahar Editor, 2002. JAMESON, F. A cultura do dinheiro: ensaios sobre a globalização. Petrópolis: Vozes, 2001.

PIMENTEL, L. Sem essa de guerra. Recife: Coqueiro, 2002.

PINHEIRO, H. \& A.C. LÚCIO. Cordel na sala de aula. São Paulo: Duas Cidades, 2001.

RESENDE, V.M. Literatura de cordel no contexto do novo capitalismo: o discurso sobre a infância nas ruas. Dissertação de Mestrado. Universidade de Brasília, 2005. Publicada em V. J. Leffa (org.). TELA 3: Textos em Linguística Aplicada. Pelotas: Universidade Católica de Pelotas, publicação eletrônica de Linguagem \& Ensino, 2005.

RESENDE, V.M. A representação da infância em situação de rua na literatura de cordel brasileira: uma análise discursiva crítica. Discurso \& Sociedad. 1 (2): 295-316, 2007.

SALLES, A. George Bush quer guerra, é inimigo da paz. Recife: Coqueiro, 2003. SILVA, G.F. Un ethnologue suisse agressé au Brésil. Rio de Janeiro: ABLC, 2000. SILVA, G.F. Enfants des rues et le massacre de la candelaria. Rio de Janeiro: ABLC, 2003. SILVA, G.F. Mahatma Gandhi. Rio de Janeiro: ABLC, s/d.

SILVA, G.F. Tobias Barreto de Menezes von Sergipe in die welt. Rio de Janeiro: ABLC, s/d.

SOUTO MAIOR, M. Painel folclórico do Nordeste. Recife: Editora da UFPE/ Fundação Joaquim Nabuco, 1981.

THOMPSON, J.B. A mídia e a modernidade. Petrópolis: Vozes, 1998.

VIANA, K. \& ROUXINOL DO RINARÉ. A grande peleja virtual de Klévisson Viana e Rouxinol do Rinaré. Fortaleza: Tupynanquim, 2003.

ZÉ DA MADALENA. Carta de Satanás ao amigo George Bush. Recife: Coqueiro, 2003. 